\title{
THE LARVAE OF THE BRITISH SPECIES OF SPIRONTOCARIS AND THEIR RELATION TO THOR (CRUSTACEA DECAPODA)
}

\author{
By Marie V. Lebour, D.Sc. \\ Naturalist at the Plymouth Laboratory
}

(Text-figs. I-4)

The general larval characters of the genus Spirontocaris are summarized by Gurney (1937b), but since his paper was written there have been published descriptions of S. spinus var. lilljeborgi (see Lebour, 1937) and of S. pusiola (see Bull, 1938). The four British Columbian species described by Needler (1933) must also be taken into consideration. With our present knowledge of all these species the description must be slightly modified. We now know the larvae of all the British species of this genus with the exception of the typical form of $S$. spinus. The specimen from which the larvae were hatched was intermediate between the typical $S$. spinus and the var. lilljeborgi and was regarded as the latter. The following species are British: S. polaris, S. spinus and its var. lilljeborgi, S. gaimardi, S. pusiola, S. occulta and S. cranchi. $S$. polaris is a northern form, the only British records being from the Shetlands. It has an abbreviated development, described by Stephensen (I9I2b, I9I6, 1935).

S. spinus var. lilljeborgi; the first larva is described from Millport (Lebour, 1937).

S. gaimardi, the first larva is described from Millport in the present paper.

$S$. pusiola, the first larva is described by Bull (1938) from Cullercoats.

$S$. occulta, all the larvae are described from Plymouth (Lebour, I932a, I936a).

S. cranchi, all the larvae are described from Plymouth (Lebour, 1932a, I936a).

The British Columbian species S. paludicola, S. tridens, S. herdmanni and $S$. brevirostris, unlike the British species, have the antennal scale without segmentation, or indistinctly segmented, and there are no marginal spines on the carapace of two of them. Otherwise they agree with $S$. occulta and $S$. cranchi which are hatched without a rostrum. The northern species described by Stephensen all have an abbreviated development. S. spinus var. lilljeborgi, S. gaimardi and $S$. pusiola are hatched with a rostrum and there is an accessory spine on the antennal endopod in S. spinus var. lilljeborgi. Bull (1938) gives a key to the known larvae of the British species (excluding $S$. polaris) but this will have to be modified to include $S$. gaimardi: 


\section{Key to the KNOWn LARVAE OF THE BRITISH SPeCIES OF SPIRONTOCARIS (EXCLUDING S. POLARIS) IN STAGE I}

I. Dorso-lateral spines at hinder end of fifth abdominal somite.

a. Rostrum well developed.

$\star$ Accessory spine on antennal endopod ... $\quad \ldots \quad$ S. spinus var. lilljeborgi

$\star \star$ No accessory spine on antennal endopod $\quad \ldots \quad \ldots \quad$... $\quad$ S. gaimardi

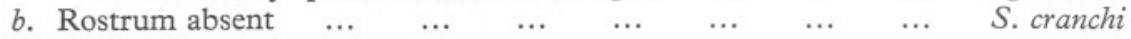

II. No dorso-lateral spines at hinder end of fifth abdominal somite.

a. With distinct but small rostral spine, dorsal side of fifth abdominal somite $\begin{array}{lllllllll}\text { without denticles } & \ldots & \ldots & \ldots & \ldots & \ldots & \ldots & \ldots & \text { S. pusiola }\end{array}$

b. Rostrum absent, dorsal side of fifth abdominal somite with a row of fine $\begin{array}{llllllllll}\text { denticles } & \ldots & \ldots & \ldots & \ldots & \ldots & \ldots & \ldots & \ldots & \text { S. occulta }\end{array}$

We may now define the larvae of the known species in the following way:

Rostrum present or absent in stage I, pointed in front. Carapace with small supra-orbital spines and with or without denticulate margin. Abdominal somite 5 with or without dorso-lateral spines. Telson rather deeply indented, in late stages with two pairs of lateral spines and twelve terminal. Anal spine present from stage I. Antennal scale segmented or not, endopod spine-like, with or without an accessory spine. Maxillule without outer seta. Exopod of maxillipede 3 with three terminal setae in stage I. Exopods on two, three or four pairs of legs. Legs 3-5 long, slender, functional. The development of certain northern species is greatly abbreviated, others may have nine larval stages.

\section{Spirontocaris gaimardi (Milne Edwards) (Fig. I $a-d$ )}

Hippolyte gaimardi Milne Edwards.

This species has been taken several times in the neighbourhood of Millport by $\mathrm{Mr}$ R. Elmhirst and Dr A. G. Nicholls. Dr Nicholls has kindly sent me the newly hatched larvae to describe. The adult resembles $S$. spinus var. lilljeborgi in having a large and conspicuous mandibular palp and in having no central tooth on the hind margin of the telson. It has epipods on the first and second legs only, thus resembling $S$. occulta and $S$. cranchi.* The larvae were hatched in April 1935. They come in between those of S. spinus var. lilljeborgi and $S$. pusiola. Thus there is a fairly long rostrum but no accessory spine on the antennal endopod, the antennal scale has only one external seta and there are denticulations antero-ventrally on the carapace.

Description of the newly hatched larva (Fig. I $c, b$ ). Length $2.9 \mathrm{~mm}$. The rostrum is long and slender ending in a point and reaching beyond the eyes. The carapace ends anteriorly in a point and there are three teeth behind this on the margin. The fifth abdominal somite has a pair of dorso-lateral spines. The telson is fairly deeply excavated posteriorly with the usual fourteen spines. The antennal scale is segmented and has one outer seta; the endopod is a simple rod ending in a spiny seta. The exopods of the maxillipedes bear

* The setobranch on leg 3 referred to by Lebour (1936b) is here disregarded. 
4, 5, 5 setae, the endopod of the second having four segments, of the third, five segments. There are rudiments of legs I-4. An anal spine is present.

It is shown that the larvae of the species of Spirontocaris vary in several ways, more than do the larvae of the species of Hippolyte. They can, however, always be distinguished from Hippolyte by the absence of the outer seta on the base of the maxillule and in the presence of an anal spine in the early stages; in the later stages the legs are always longer and functional and there are usually more exopods on the legs. The characters of the larvae of Hippolyte are summarized by Gurney (I937 $b$ ).

Attention has been drawn (Lebour, I936a) to the great similarity between Spirontocaris cranchi and the genus Thor, both of which have lost the mandibular palp, but Spirontocaris cranchi in other ways resembles S. occulta so strongly that it seems impossible to remove it from that genus. Zariquiey (I935) has actually attributed S. cranchi to the genus Thor, but it is inadvisable
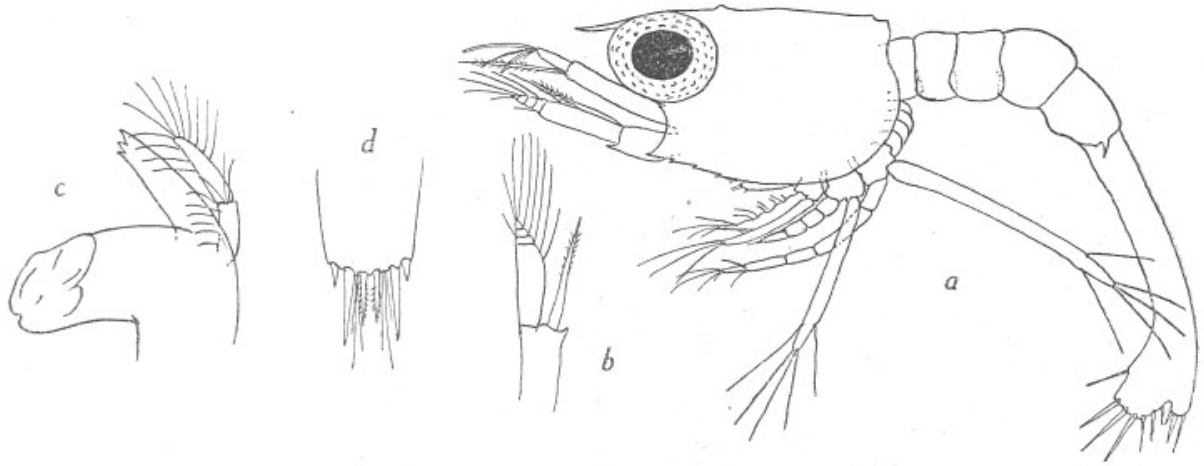

Fig. I. Spirontocaris gaimardi: a, newly hatched larva, $2.8 \mathrm{~mm}$. long; $b$, antenna; $c$, mandible of adult; $d$, end of telson of adult.

to follow him in this respect, especially as we now almost certainly know the larvae of Thor which show generic differences from those of Spirontocaris cranchi.

Whilst working at the Bermuda Biological Station in I938-9, I found a conspicuously coloured and very small Hippolytid larva which occurred commonly in the plankton from fairly shallow water. The first stage was caught in the Reach at night, but it also occurred with the other stages outside Castle Harbour. The last larva changed to the post-larva in the laboratory, and the post-larva to the first young stage. In this last, the latest stage obtainable, the rostrum was very short; there was a leaf-like process, apparently movable, on the distal segment of the antennular peduncle; the external ramus of the antennule was very much swollen, and the carpus of the second leg was divided into four segments. There were no traces of epipods on the legs. From these characters it seemed almost certain that here was the missing larva of Thor. Verrill (I922) has recorded T. paschalis from Bermuda, having dredged berried females in the shallow waters of the Reach 
among weed, but subsequent efforts to obtain it have been unsuccessful. It is a common species on the Florida coast and in many other parts of the world, but the Bermuda form according to Verrill, differed slightly from the type, having only five segments in the carpus of the second leg and a shorter rostrum with fewer teeth. As the larvae were obtained both in the Reach (early stages only) and outside (all stages) commonly in spring and summer, it is very probable that one at least of the habitats of the adult is in the shallow water outside among the weeds and rocks where it is almost impossible to dredge.

The chief peculiarity of the larva is its extremely broad rostrum which is triangular, slightly broader at the base than at the sides and ending in a rounded angle anteriorly. This rostrum is unlike that of any known larva. No teeth had appeared even in the first young stage, although the rostrum had become more pointed and very much the shape of a young form figured by Verrill, which, however, had three teeth.

All the larvae were coloured bright red with many chromatophores on a yellow ground, there being two red streaks from the thorax right along the abdomen.

\section{The Larval and Young Stages of THOR (Figs. 2-4)}

First larval stage (Fig. $2 a-g$ ). Length $2 \mathrm{~mm}$. or less. The eyes are not free. The rostral region is rounded, but there is no true rostrum. The carapace ends anteriorly in a point, and there are three denticles behind it on the ventral margin. The dorsal organ is conspicuous behind the eyes, and there is a small prominence in front of the posterior end of the carapace dorsally. There are no spines on the abdominal somites, and there is no anal spine. The telson is indented in the centre and has the usual fourteen spines. The antennule is short with an unsegmented peduncle bearing at its end a long seta internally, representing the endopod, with a thin hair, and a thick terminal process bearing three aesthetes and a hair. The antennal scale is segmented at the tip with two outer setae and nine inside and round the tip, the endopod being represented by a short thick rod bearing a long seta with a short accessory seta. The mandible has the molar process already beginning to be separated from the incisor portion. The maxillule has no seta on its base; the endopod has five setae. The maxilla has a setose endopod with three lobes, bearing three setae terminally and 2, 2, 2 setae on the lobes, and five setae on the exopod. The exopods of the maxillipedes bear five setae, three terminal. There is a rudiment of the first leg.

The second larval stage. Length ca. $2 \mathrm{~mm}$. (sometimes slightly less or more). This is very like the first, but has the eyes and rostrum free and the usual extra pair of spines internally on the telson. There are no supra-orbital spines, but the antennal spine is present.

The third larval stage (Fig. $2 h-k$ ). Length $2-2.8 \mathrm{~mm}$. The larvae vary in size and development, but none of them have the base of the uropods separated. 
The telson is cut off from the sixth abdominal somite. There are rudiments of the second to the fourth legs, the first being functional. The exopods of
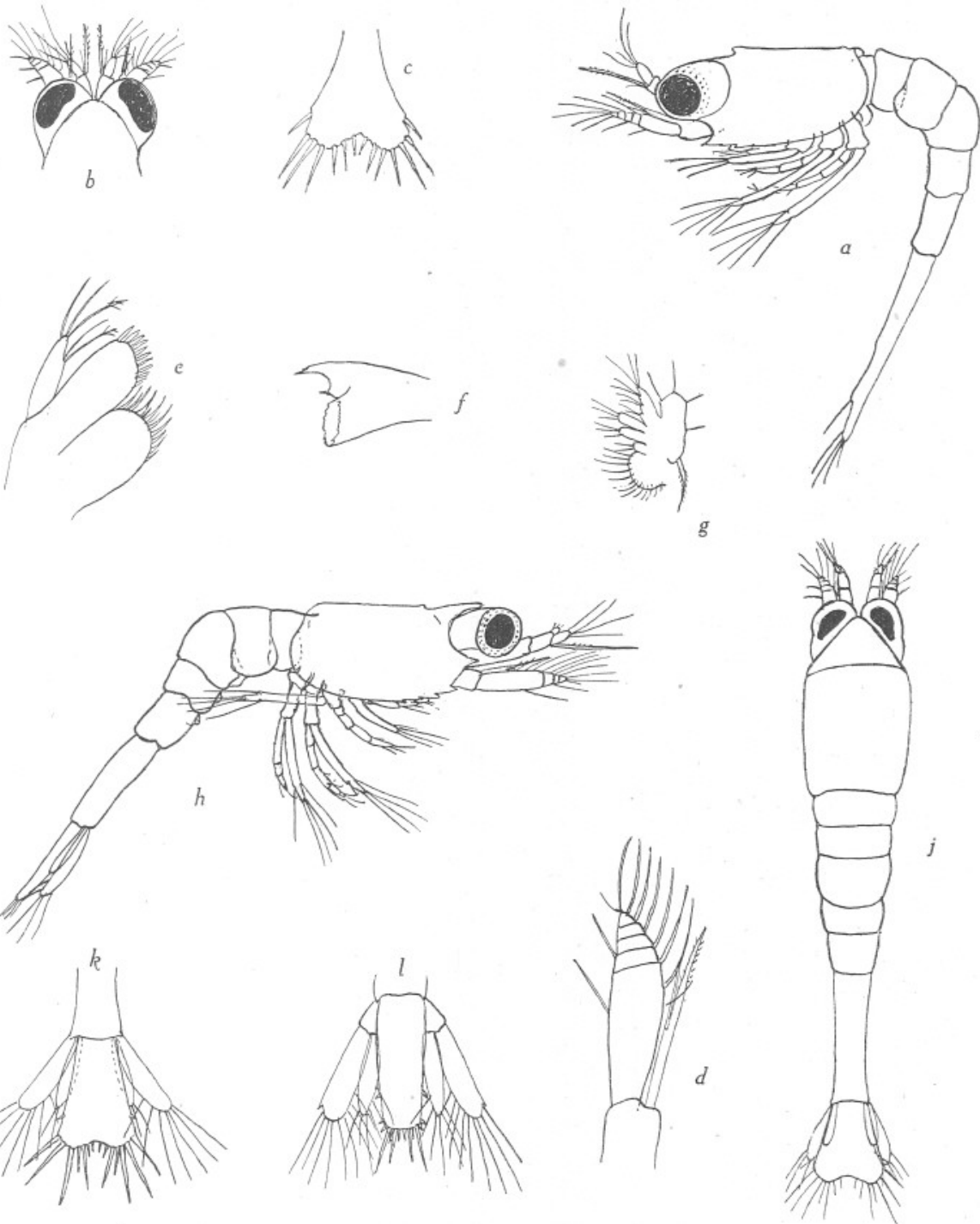

Fig. 2. Thor: $a$, first larval stage, $2 \mathrm{~mm}$. long; $b$, head region; $c$, telson; $d$, antenna; $e$, maxillule; $f$, mandible; $g$, maxilla; $h$, third larval stage, $2.5 \mathrm{~mm}$. long; $j$, dorsal view; $k$, telson of more advanced third stage; $l$, fourth larval stage, telson.

the second and third maxillipedes and the first leg have four terminal setae, the second maxillipede with one lateral, the third and leg I with two. In the larger specimens the pleopods show beneath the cuticle. The inner uropod 
has no setae in the smaller forms but in the larger specimen there are two, and in these the outer seta of the telson has become tooth-like.

The fourth larval stage (Fig. $2 l$ ). Length $c a .2 .7 \mathrm{~mm}$. or rather longer, varying much. Small pleopods are now present, the second leg is functional, the other three rudimentary. Legs I and 2 bear exopods, but the others are simple rods. The telson is nearly straight-sided and the uropods have a distinct base. There is a spine each side just above the posterior third, the following one tooth-like near the angle, and ten terminal spines. The antennal endopod has lost the accessory spine.

The fifth larval stage (Fig. $3 a, b$ ). Length $3.6 \mathrm{~mm}$. The rostrum is still a blunt triangle, the carapace is pointed in front with the three antero-ventral denticles. There are no supra-orbital spines but there is an antennal spine. The first and second legs are chelate, their exopods bear eight setae, the third to the fifth legs are not functional and are scarcely jointed and held under the abdomen. The pleopods are long but without setae. The telson has two pairs of lateral spines and ten terminal spines, the second from the outside being the longest, and the hind margin is slightly convex. There is now an anal spine. The mandible is distinctly cleft.

The sixth larval stage. Length $4 \mathrm{~mm}$. This stage moulted to the post-larva. It was very little larger than stage 5 and very similar, but slightly farther advanced in development. All the legs are longer and jointed, but the third to the fifth are hardly functional. The pleopods are long but not setose.

The post-larva from the last larva (Fig. $3 c-g$ ). Length $4 \mathrm{~mm}$. The anterior angle of the carapace is rounded and there are no ventral denticles. The antennal spine alone remains. The antennule shows rudiments of the distal plate. The rostrum is still a broad triangle, rounded, but rather more pointed, in front. There are remains of exopods on legs I and 2, but no epipods. The carpus of the second leg is divided into three segments. Legs $3-5$ are long and slender, the dactyl ending in a tooth with two inner teeth. The pleopods are setose. The telson has two pairs of lateral spines and six terminal with two hairs. The fifth abdominal somite has a very small postero-lateral tooth: and the fourth ends sharply almost in a tooth and there are hairs at the edges of these somites.

The post-larva moulted to a first young stage.

The first young stage (Figs. $3 h, j, 4 a-g$ ). Length $3.6 \mathrm{~mm}$. In this stage there is a distinct hinged plate on the distal segment of the antennular peduncle. The outer antennular flagellum is very thick at the base and composed of seven segments. The antennal flagellum is about twice as long as the carapace. The rostrum is short, pointed, with a very broad base, but has no teeth. The appendages closely resemble those of Thor paschalis in shape. The carpus of the second leg has four segments. Legs 3-5 end in toothed dactyls. The telson is convex terminally with six terminal setae and a pair of long hairs, but no central tooth. There are no epipods and there is no trace of a mandibular palp. 

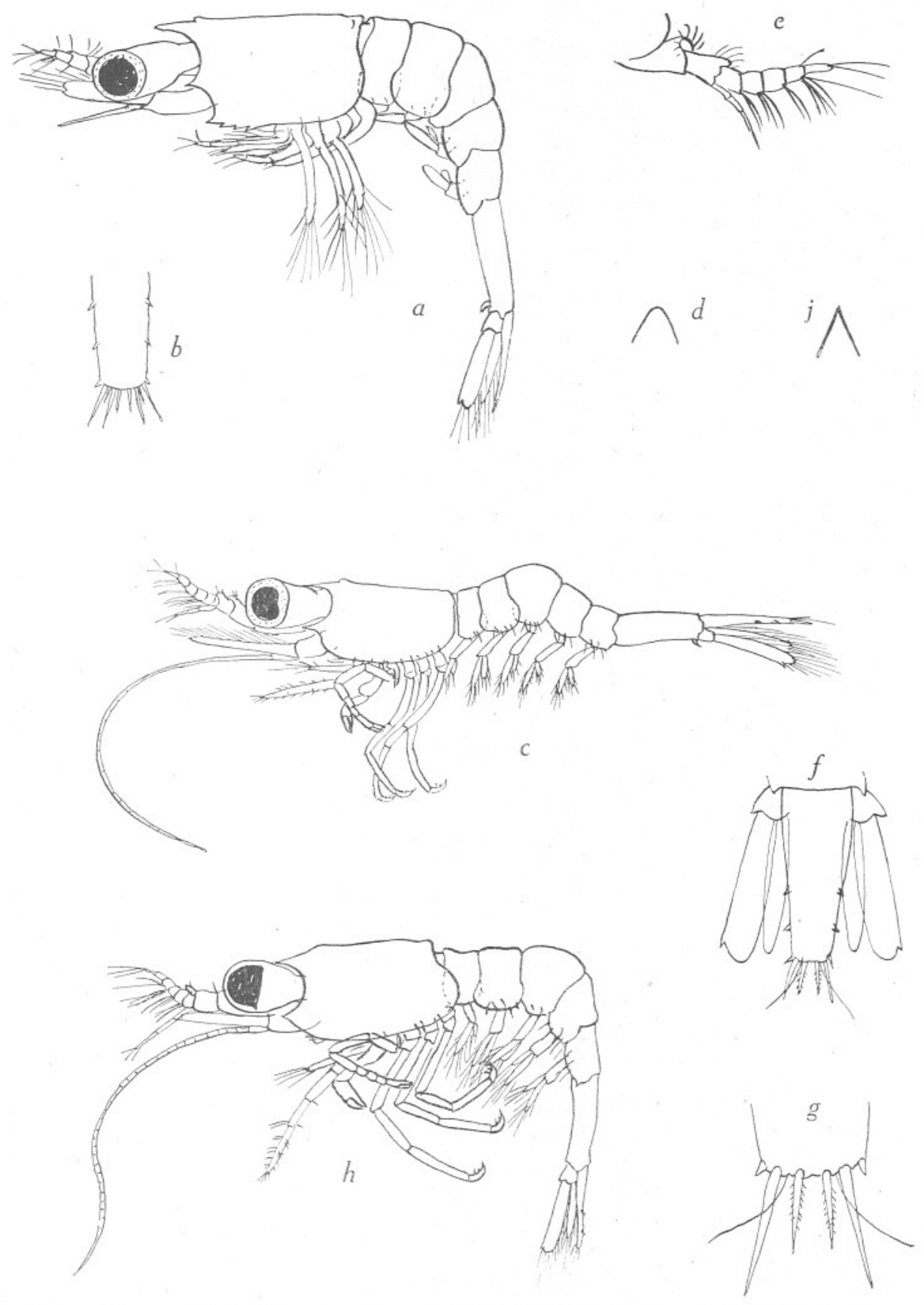

Fig. 3. Thor: $a$, fifth larval stage, $3.6 \mathrm{~mm}$. long; $b$, telson; $c$, post-larva from last larva, $3 \mathrm{~mm}$. long; $d$, rostrum; $e$, antennule; $f$, telson; $g$, end of telson; $h$, first young stage from postlarva, $3.6 \mathrm{~mm}$. long; $j$, rostrum. 
No later stages were procurable but it seems certain that this is the larva of $T$. paschalis. This species (or possibly a variety) has been recorded from Bermuda and there cannot be a doubt of the truth of the record, judging by Verrill's figures. No species of Spirontocaris have ever been found there and it is here shown that the larva differs from both that genus and from Hippolyte. The characters of the first young stage show that it is very close
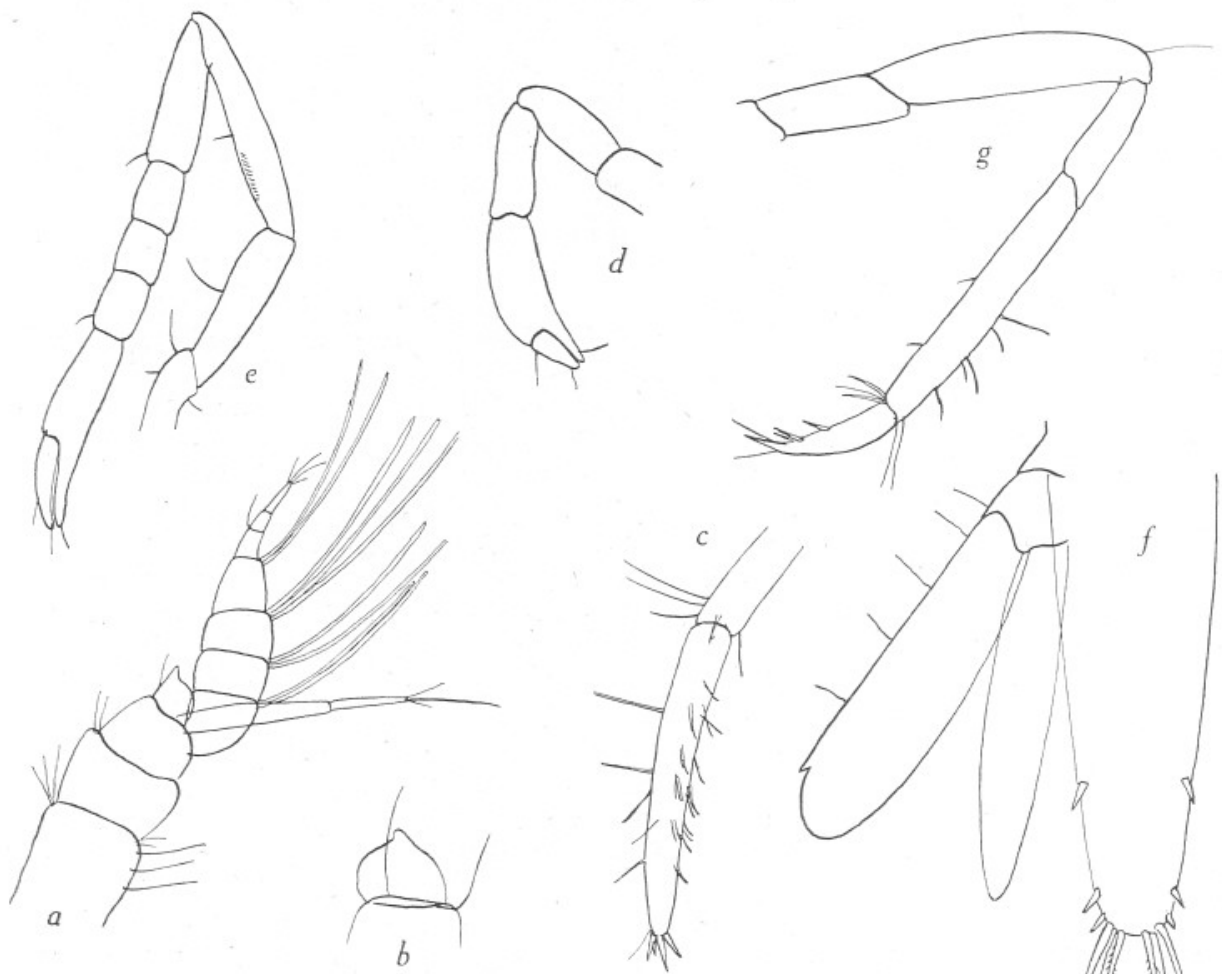

Fig. 4. Thor, first young stage: $a$, antennule; $b$, leaf-like process on antennule; $c$, end of third maxillipede; $d$, first leg; $e$, second leg; $f$, telson; $g$, last leg.

to Thor, having the characteristic plate on the distal segment of the antennular peduncle, no supra-orbital spines, no epipods, the carpus of the second leg divided into four segments (there being five in the Bermuda form of Thor according to Verrill), a very broad and short rostrum and no mandibular palp (this last character is not significant, as it has been shown that in Spirontocaris occulta the palp does not appear in the first young stages (Lebour, I936a).

The differences in the larva fully warrant the separation of Thor from Hippolyte and Spirontocaris, although it is obviously related to them and has certain characters of both. The rostrum is unlike that of any known decapod larva. 
The adult Thor closely resembles Spirontocaris cranchi, but the larva differs much more from this species than it does from S. spinus var. lilljeborgi, having an accessory spine on the antennal endopod as in that species. The fact that there are no epipods on the legs at once separates it from S. cranchi, the only species of Spirontocaris in which the mandibular palp is wanting and which has epipods on legs I and 2. Those species of Spirontocaris which lack epipods (see Rathbun, I926) are of an entirely different type, having the usual two-segmented mandibular palp.

The larval characters of Thor may now be given in order to compare them with the other genera of the Hippolytidae:

Rostrum absent in stage I, the front margin rounded; in the following stages it forms a broad triangle, the front being rounded. Carapace without supra-orbital spines; denticles on the antero-ventral margin.

Abdominal somite 5 without dorso-lateral spines. Telson fairly deeply indented, in late stages with two pairs of lateral spines and ten terminal. Anal spine not present in early stages but present in the two last.

Antennal scale segmented with two outer setae, endopod spine-like with accessory spine. Maxillule without outer seta. Exopods on legs I and 2, exopods of third maxillipede with three terminal setae. Six larval stages.

\section{Key to the LaRvae of the Genera SPIRONTOCARIS, HIPPOLYTE AND THOR}

A. Rostrum pointed.

I. No external seta at base of maxillule [dorso-lateral spines on fifth abdominal somite present or absent; accessory spine on antennal endopod present or absent; supra-orbital spines small; anal spine present in all stages]

Spirontocaris

2. External seta at base of maxillule [dorso-lateral spines on fifth abdominal somite present, no accessory spine on antennal endopod; supra-orbital spines absent or minute in early stages; anal spine present only in later stages]

Hippolyte

B. Rostrum very broad, triangular, rounded in front [no dorso-lateral spines on fifth abdominal somite; antennal endopod with accessory spine; no external seta at base of maxillule; no supra-orbital spines; anal spine present only in later

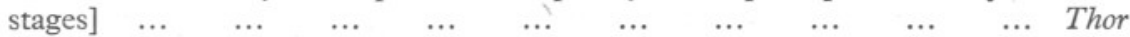

The genera Hippolyte, Spirontocaris, Thor, Chorismus and Caridion are all included in the group of the Hippolytidae as defined by Calman (I906) and Kemp (I9I4) which have no arthrobranchs on the peraeopods and possess an incisor process on the mandible. The larvae give additional evidence that the existing classification of these forms is a natural one. Caridion approaches nearest to the Pandalidae and also has certain characters which approach Lysmata. Chorismus (see Gurney, I937b) has an abbreviated development but in essentials it is not unlike the others, except in having more spines on the telson. All in this group agree in having a compact body, not specially elongated, the fifth leg not unusually long and never prematurely developed, in having the exopod of the third maxillipede in stage I ending in three setae, 
in the telson being broad and somewhat indented in the posterior margin, in the absence of dorsal spines on any of the abdominal somites and in the absence of posterior spines on the ventral margin of the carapace or in the centre, the eyes being normal and not specially long. This group of larvae differs very appreciably from all the other Hippolytid larvae known. Gurney (I937b), in summarizing the larval characters of the Hippolytid genera, has shown that there are four types of larvae in Lysmata, Hippolysmata, Tozeuma, Saron and Latreutes, those of Lysmata and Hippolysmata being very similar, all four for the most part differing greatly from one another and that it is not as yet possible to group these further in any natural system. The finding of the larva of Thor, one of the desiderata mentioned in his work, has, however, advanced us a step in showing that this genus undoubtedly takes its place near Spirontocaris and Hippolyte.

\section{LITERATURE}

All the literature relating to the larvae is referred to by R. Gurney, Bibliography of the Larvae of Decapod Crustacea. Ray Society, I939.

Calman, W. T., I906. Notes on some genera of the crustacean family Hippolytidae. Ann. Mag. Nat. Hist., Ser. 7, Vol. xvir, pp. 29-34.

Kemp, S., I9I4. Notes on Crustacea Decapoda in the Indian Museum. V. Hippolytidae. Rec. Indian Mus., Vol. x, Part II, No. 4, pp. 8I-I29.

Rathbun, M. J., I904. Decapod Crustaceans of the northwest coast of North America. Harriman Alaska Expedition, Vol. x, pp. I-I90.

Verrill, A. E., I922. Decapod Crustacea of Bermuda. Part II. Macrura. Trans. Connecticut Acad. Arts Sci., Vol. xxvi, pp. I-I79.

ZARIQUiEY, R. (Cennarro), I935. Crustáceos del Mediterráneo (Decap. Macrur.) Familia Hippolytidae S. Bate, Generos Thor Kingsley, Spirontocaris S. Bate. Bull. Ist. Catalana d'Hist. Nat. Vol. xxxv, Quart. Trimestre, pp. I-I8. 